\title{
Non-invasive ventilation during sleep: time to define new tools in the systematic evaluation of the technique
}

\author{
Mark W Elliott
}

\section{Correspondence to}

Mark W Elliott, Department of Respiratory Medicine, St James's University Hospital, Beckett Street, Leeds LS9 7TF, UK; mwelliott@doctors.org.uk

Received 6 May 2010 Accepted 11 May 2010 Published Online First 20 August 2010

\begin{abstract}
Non-invasive ventilation (NIV) has been remarkably effective in the management of chronic respiratory failure, despite initially rudimentary equipment and limited understanding of what was actually happening, minute by minute when ventilation was applied. Modern ventilators, controlled by complex algorithms, and with integrated monitoring allow for sophisticated customisation of ventilatory support to an individual. However, if problems with ventilation are not recognised, and their significance understood, they cannot be fixed. Experience of monitoring during sleep from patients predominantly with sleep apnoea can be transferred and extended to patients receiving NIV. This article, the first in a series, explores the rationale for NIV and how its application to an individual patient can be monitored using simple tools and, when problems are identified, the causes can be identified using sophisticated interpretation of more detailed monitoring. This requires a detailed understanding of how different modes of ventilation work and some knowledge of the algorithms that control each machine. These themes are explored in this article and developed in subsequent articles in the series.
\end{abstract}

Non-invasive ventilation (NIV) has been part of mainstream respiratory medicine for approximately 20 years. In the early days ventilators were simple blowers with rudimentary controls and insensitive triggers. Mask cushions were made of vinyl, which hardened over time with use, and the choice was limited. Significant leak could be a problem for many patients, even during daytime use, and ventilators did not always respond well to changing patterns of breathing. That ventilation was being delivered effectively during sleep was often assumed rather than proven, even in research studies. Furthermore, the appropriate therapeutic end point during NIV remained uncertain. Despite not knowing what ought to be achieved, not measuring what was being achieved and at best using only basic tools, NIV used during sleep was remarkably effective in restrictive patients in improving survival, sleep quality and daytime health status!

Modern ventilators are controlled by sophisticated algorithms, which make them very sensitive to changing patterns of breathing. There is an enormous variety of masks made of substances which conform well to a patient's features, so that it is usually possible to minimize leak. There is a clearer understanding of what should be achieved during assisted ventilation and why, and the technology is available to monitor important parameters through the ventilator itself or external stand-alone devices. Despite this, monitoring during NIV remains rudimentary. In a patient who is doing well and tolerating NIV, this is usually adequate. However, when the patient tolerates NIV poorly, or does not derive symptomatic benefit, more sophisticated monitoring is required; if a problem cannot be identified it cannot be fixed. This is the first article in a series, which explores these issues in greater detail.

\section{WHAT NEEDS TO BE FIXED BY NIV?}

To understand how assisted ventilation helps patients, an understanding of the pathophysiology of ventilatory failure and the way in which ventilators work is required. For unassisted breathing to be effective the respiratory muscle pump must have the capacity to sustain ventilation against a given load. It also requires neural drive from the central nervous system. In other words, there needs to be a balance between load and capacity, with the system receiving adequate drive.

Capacity may be reduced either because of intrinsic weakness of the respiratory muscles, which can be reversible (due to electrolyte disturbance (hypo- or hyperkalaemia, hypermagnesaemia, hypoxia, hypercapnia or acidosis) or irreversible (due to neuromuscular disease), or because muscles of normal strength are working at a mechanical disadvantage, for instance because of hyperinflation $^{1}$ or chest wall deformity. A reduction in capacity is not an 'all or nothing' phenomenon nor is it static. Rather it is a continuum, which may change minute by minute. When the respiratory muscle pump starts to fail the pattern of breathing changes, with an increase in respiratory rate and a fall in tidal volume. ${ }^{2}$ This pattern of breathing reduces the demand upon the respiratory muscles, but at the expense of alveolar ventilation. Hypercapnia and acidosis ensue, which further reduce muscle function. ${ }^{3}$

In the same way there can be reversible and irreversible changes in the load against which the respiratory muscle pump is working. Load may be excessive because of reduced compliance of the chest wall, for example due to scoliosis, or of the lungs due to diseases of the airways or lung parenchyma. Neuromuscular disease may increase load because of the development of atelectasis. Abnormalities of the pulmonary vasculature, such as occur in chronic obstructive pulmonary disease (COPD) and scoliosis, may put a secondary load on the respiratory muscles by the need for increased ventilation to maintain adequate gas exchange. The 
load against which the respiratory muscle pump is acting is not constant. Changes may occur either because of disease (eg, sputum or fluid retention or increased airflow obstruction) or as part of normal circadian physiological changes (eg, during sleep, loss of tone in the muscles of the upper airway leads to increased upper airway resistance).

Neural drive may be reduced because of structural abnormalities of the respiratory control centre in the brainstem or due to sedative drugs. Individuals who develop chronic ventilatory failure may also have secondary abnormalities of drive occurring as a consequence of changes during sleep. Ventilation is reduced during sleep in normal individuals because of the loss of the wakefulness drive to breathe. A rise in $\mathrm{CO}_{2}$ of up to $1 \mathrm{kPa}$ is normal, but if excessive causes a transient acidosis, which results in a compensatory renal retention of bicarbonate. As a result chemosensitivity to $\mathrm{CO}_{2}$, which is mediated by changes in $\mathrm{pH}$, is reduced. In addition, patients with chronic ventilatory failure often have disturbed sleep, and this may lead to abnormal ventilatory responses to both hypoxia and hypercapnia by day. 4

\section{HOW ARE THESE PROBLEMS FIXED BY NIV?}

The exact way in which NIV has an effect that carries over into the time when the patient is not receiving ventilatory support remains incompletely understood, but available data suggest that restoration of central drive and resetting of the ventilatory response to $\mathrm{CO}_{2}$ is the most important factor, at least in explaining improvements in diurnal blood gas tensions. ${ }^{5-7} \mathrm{~A}$ reduction in $\mathrm{CO}_{2}$ tensions during ventilation seems to be key; this is not surprising as it indicates effective ventilation and fits with our understanding of the pathophysiology of chronic ventilatory failure. A reduction of $\mathrm{CO}_{2}$ during ventilation will render the patient slightly alkalotic and there will be excretion of bicarbonate and restoration of chemosensitivity to $\mathrm{CO}_{2}$. However, ventilation that reduces $\mathrm{CO}_{2}$ will usually also have some effect in offloading respiratory muscles, and it is likely that the pressures delivered will be of sufficient magnitude to have an impact upon lung mechanics, either by recruiting atelectatic lung or by stretching narrowed airways. In patients with COPD, Diaz et al demonstrated improvements in lung function and 6 minute walking distance as well as improved blood gas tensions following 3 weeks of NIV delivered for $3 \mathrm{~h}$ per day, 5 days per week. $^{8} 9$ These studies showed that even such an apparently limited duration of ventilation during the daytime is associated with a significant effect of NIV. The authors confirmed an effect of NIV, demonstrating an increase in tidal volume and reduction in $\mathrm{PaCO}_{2}$. This underlines the fact that the quality of ventilation delivered is a key issue when assessing the effects of NIV. Unfortunately no data are presented about the effects of NIV during the night in the majority of studies evaluating the longterm effects of NIV. A reduction in $\mathrm{CO}_{2}$ should be the primary aim of assisted ventilation and how this can be monitored is addressed in the second paper in this series by Janssens et al. This paper will propose a decision tree for monitoring NIV during sleep using simple tools such as oximetry, transcutaneous $\mathrm{PCO}_{2}$ and inbuilt ventilator software.

So far the discussion has focused on the effect of NIV upon diurnal arterial blood gas tensions, and indeed an improvement in diurnal $\mathrm{PaO}_{2}$ and $\mathrm{PaCO}_{2}$ is usually taken as a marker of successful ventilation. However, patients receiving domiciliary ventilation often report an improved sense of well-being and better quality sleep, as well as a reduction in the sensation of breathlessness, and large improvements may occur with only small changes in arterial blood gas tensions. A number of studies have reported severe sleep disruption in patients with both $\mathrm{COPD}^{10}$ and neuromuscular/chest wall deformity, ${ }^{11}$ and this can be improved with NIV. ${ }^{12-15}$ That NIV should improve sleep quality is at first sight surprising; encumbrance with mask and head gear and then having cold air blown into the upper airway has the potential to disrupt sleep. However, experience in patients with sleep apnoea hypopnoea syndrome has shown overwhelmingly that correction of sleep-related abnormalities of breathing improves sleep quality notwithstanding the inconvenience of mask, positive pressure, etc. Effective control of nocturnal hypoventilation, without compromising, and ideally improving, sleep quality, with improved well-being during the day is the aim of NIV during sleep. When this is not achieved, further evaluation is needed. Sleep hypoxaemia/hypercapnia and sleep deprivation and fragmentation are now recognised to be key factors for the development of hypertension and diabetes. These co-morbidities may also be important in patients with chronic respiratory failure. Further research should be directed at establishing whether cardiovascular and metabolic outcomes affect survival and quality of life in patients with chronic respiratory insufficiency and whether these can be impacted by NIV; this will determine what should be monitored, and achieved, during NIV.

\section{HOW CAN PROBLEMS DURING NIV BE FIXED?}

If a patient does not tolerate NIV, or the effect is less than expected, the problems need to be identified. This will start with an evaluation of NIV during wakefulness. Obvious problems with the mask or head gear should be identified. The patient should then be observed during NIV, looking for leak or patient-ventilator asynchrony; this will usually be visible to an experienced observer, but may be more obvious with objective monitoring. To understand the cause of any problems observed, and to provide a solution, it is vital that account be taken of the type of ventilator being used and the way that it triggers into inspiration and cycles into expiration. This can vary between apparently similar machines and may have a major effect upon patient-ventilator interaction. The principles of ventilator function are explored in the third paper in this series by Rabec et al. Even if ventilation is adequate during daytime NIV there can still be sleep-induced problems, because of the interface being moved during sleep, leading to excessive leak, and because of changes in upper airway function, lung mechanics and the control of breathing. Leaks have been shown to disrupt sleep, ${ }^{16}$ though others have shown remarkably effective control of nocturnal ventilation, reasonable sleep quality and long-term acceptance in established users with considerable leak overnight. ${ }^{17} 18$ Notwithstanding the potential for leaks to disrupt sleep, they may compromise effective control of nocturnal hypoventilation and they should be minimised. Hyperventilation induced by NIV may also provoke undesirable respiratory events by promoting active glottic closures and precipitate central apnoeas, affecting the efficacy of ventilation but also the quality of sleep. When problems have been documented using simple techniques, such as oximetry or $\mathrm{PtCO}_{2}$ measurements, analysis of polygraphic or polysomnographic recordings may help to optimise NIV during sleep. The fourth paper in this series by Gonzalez et al summarises the observations of a working group (SomnoNIV) which describe a classification of polygraphic recordings during NIV. This is a new area in sleep and respiratory medicine, and it is time for clinicians and researchers to use the same language and the same methodology for evaluating NIV efficacy during sleep. 


\section{CONCLUSION}

The aetiology of chronic ventilatory failure is likely to be multifactorial, with different factors assuming greater or lesser degrees of importance even in patients with the same condition. Indeed in an individual patient there may be differences at various stages of the illness. The same is true for the mechanism of benefit from NIV. With the current state of knowledge, when NIV is used in chronic ventilatory failure the primary aim should be to control nocturnal hypoventilation and this should be confirmed objectively. Polygraphy is not necessary in every patient receiving NIV. However, the patient who is not tolerating, or benefiting from, NIV should be carefully evaluated during wakefulness and then during sleep, and this should include respiratory polygraphy. To understand the data available it is important to understand how the ventilator functions. This series provides a theoretical basis for further evaluation, but more research is needed to understand fully the importance of subtle abnormalities identified during NIV to patient well-being and their experience of NIV.

Competing interests MWE has received honoraria for lecturing on non-invasive ventilation at meetings organised by Phillips Respironics Japan and Astra Zeneca (UK).

Provenance and peer review Commissioned; not externally peer reviewed.

\section{REFERENCES}

1. Macklem PT. Hyperinflation. Am Rev Respir Dis 1984:129:1-2.

2. Tobin MJ, Perez W, Guenther SM, et al. The pattern of breathing during successful and unsuccessful trials of weaning from mechanical ventilation. Am Rev Respir Dis 1986;134:1111-18.

3. Juan G, Calverley P, Talamo C, et al. Effect of carbon dioxide on diaphragmatic function in human beings. $N$ Engl J Med 1984;310:874-9.
4. White DP, Douglas NJ, Pickett CK, et al. Sleep deprivation and control of ventilation. Am Rev Respir Dis 1983;128:984-6.

5. Nickol AH, Dunroy $\mathrm{H}$, Polkey Ml, et al. A quick and easy method of measuring the hypercapnic ventilatory response in patients with COPD. Respir Med 2009;103:258-67.

6. Nickol AH, Hart N, Hopkinson NS, et al. Mechanisms of improvement of respiratory failure in patients with COPD treated with NIV. Int J Chron Obstruct Pulmon Dis 2008;3:453-62.

7. Annane D, Quera-Salva MA, Lofaso F, et al. Mechanisms underlying effects of nocturnal ventilation on daytime blood gases in neuromuscular diseases. Eur Respir $J$ 1999;13:157-62

8. Diaz $\mathbf{0}$, Begin $\mathrm{P}$, Torrealba $\mathrm{B}$, et al. Effects of noninvasive ventilation on lung hyperinflation in stable hypercapnic COPD. Eur Respir J 2002;20:1490-8.

9. Diaz 0, Begin $\mathrm{P}$, Andresen $\mathrm{M}$, et al. Physiological and clinical effects of diurnal noninvasive ventilation in hypercapnic COPD. Eur Respir J 2005;26:1016-23.

10. Calverley PMA, Brezinova V, Douglas NJ, et al. The effect of oxygenation on sleep quality in chronic bronchitis and emphysema. Am Rev Respir Dis 1982:126:206-10.

11. Sawicka EH, Branthwaite MA. Respiration during sleep in kyphoscoliosis. Thorax 1987:42:801-8.

12. Elliott MW, Simonds AK, Carroll MP, et al. Domiciliary nocturnal nasal intermittent positive pressure ventilation in hypercapnic respiratory failure due to chronic obstructive lung disease: effects on sleep and quality of life. Thorax 1992;47:342-8.

13. Ellis ER, Bye PT, Bruderer JW, et al. Treatment of respiratory failure during sleep in patients with neuromuscular disease. Positive-pressure ventilation through a nose mask. Am Rev Respir Dis 1987;135:148-52.

14. Meecham Jones DJ, Paul EA, Jones PW, et al. Nasal pressure support ventilation plus oxygen compared with oxygen therapy alone in hypercapnic COPD. Am J Respir Crit Care Med 1995:152:538-44.

15. Barbe F, Quera-Salva MA, de Lattre J, et al. Long-term effects of nasal intermittent positive pressure ventilation on pulmonary function and sleep architecture in patients with neuromuscular diseases. Chest 1996;110:1179-83.

16. Teschler H, Stampa J, Ragette R, et al. Effect of mouth leak on effectiveness of nasal bilevel ventilatory assistance and sleep architecture. Eur Resp $\mathrm{J}$ 1999:14:1251-7.

17. Tuggey JM, Elliott MW. Randomised crossover study of pressure and volume noninvasive ventilation in chest wall deformity. Thorax 2005;60:859-64.

18. Windisch W, Storre $\mathbf{J H}$, Sorichter $\mathrm{S}$, et al. Comparison of volume- and pressurelimited NPPV at night: a prospective randomized cross-over trial. Respir Med 2005;99:52-9 